\title{
Erratum to: increased record-breaking precipitation events under global warming
}

\author{
Jascha Lehmann ${ }^{1,2} \cdot$ Dim Coumou ${ }^{1} \cdot$ Katja Frieler $^{1}$
}

Published online: 5 August 2015

(C) Springer Science+Business Media Dordrecht 2015

Erratum to: Climatic Change (2015)

DOI 10.1007/s10584-015-1434-y

In the original publication Fig. 4 is a duplicate of Fig. 5a. The correct Fig. 4 is given here:

The online version of the original article can be found at http://dx.doi.org/10.1007/s10584-015-1434-y.

Jascha Lehmann

jascha.lehmann@pik-potsdam.de

1 Potsdam Institute for Climate Impact Research, Telegrafenberg A26, 14473 Potsdam, Germany

2 University of Potsdam, Potsdam, Germany 


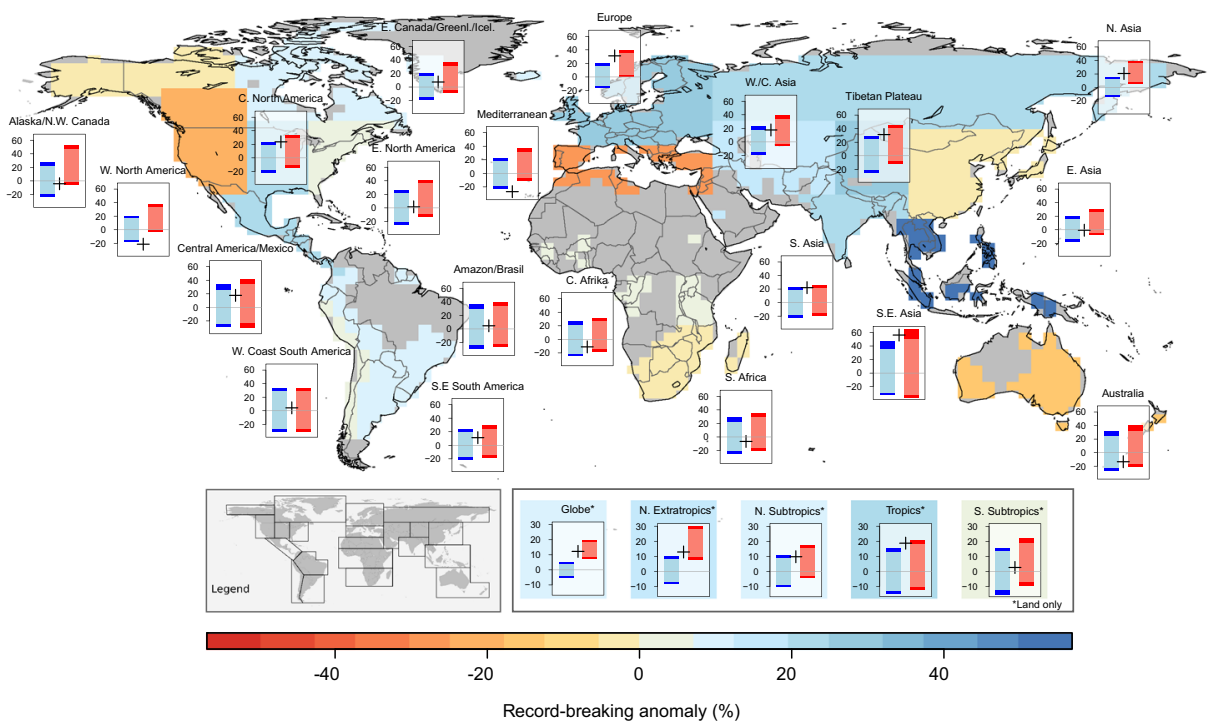

Fig. 4 Annual observed record-breaking anomaly between 1981 and 2010. The magnitude is indicated by different colors at grid cells which contributed to the regional record-breaking anomaly. For each region a separate diagram is shown which includes the observed record-breaking anomaly (+ symbol) and the 90 and $95 \%$ confidence interval estimates from the iid-model (blue bars) and the Clausius-Clapeyron model (red bars). Lower panels show the same results for the global mean and the four latitudinal belts (same regions as in Figs. 2 and 3) 